\title{
Technology: changing the focus of medical education?
}

This article was published in the following Dove Press journal:

Advances in Medical Education and Practice

7 February 2014

Number of times this article has been viewed

\section{Sayinthen Vivekanantham \\ Rahul Prashanth Ravindran}

Faculty of Medicine, Imperial College London, London, UK
Correspondence: Sayinthen

Vivekanantham

Faculty of Medicine, Imperial College London, London, SW7 2AZ, UK, Tel +442075895 I I I

Email sayinthen@vivekanantham.com

\section{Dear editor}

With technology advancing at such a fast rate, our ability to look up and use information quickly and efficiently has improved significantly. With electronic devices capable of accessing information becoming more prevalent within the hospital setting, how this could influence medical education should be brought into question.

As we are now able to look up information quickly within the clinical setting, we ask whether medical students should be expected to learn information that can easily be looked up. Instead, we question whether they should use their time to learn skills related to the application of the information, as well as information that would be needed in acute situations where looking up information would not be pragmatic.

Currently, medical technology is advancing at a rapid pace. ${ }^{1}$ Knowledge that would have taken many years to learn can be stored on devices that we all carry with us, and with further improvements in technology, the speed, quantity, and efficiency with which we are able to look up information is set to improve even further. Detailed clinical knowledge on obscure conditions that are not encountered regularly can now be looked up in a matter of seconds. We question whether the requirement to recall knowledge in these situations is now still important, and truly in the best interests of the patient. We wonder whether our time during training would be better spent concentrating on practical procedures or enhancing our searching skills to find relevant information faster, rather than rote learning.

Initiatives are underway to correlate presenting symptoms through algorithms where differentials are automatically produced in order of likelihood, and a study demonstrated that a Google search was helpful in medical diagnosis. ${ }^{2}$ Furthermore, protocols and frameworks are increasingly being published to cover different clinical situations, ${ }^{3}$ which have made medicine more systematic and documented in recent years. All this information is easy to access on personal electronic devices. One potential benefit that this approach may offer is reduced training times for clinicians. Furthermore, advice to clinicians could be updated centrally, based on the latest evidence, meaning that clinicians could treat patients according to the best information available at that point in time. Increasing digitalization also makes auditing of clinical work easier, with the potential to access additional services that can offer further efficiency benefits.

We do acknowledge, however, that having a strong foundation of knowledge will allow clinicians to build upon their knowledge, which may not be possible if facts must constantly be looked up. Furthermore, medicine is often thought to be an art as 
much as a science - computing devices may be able to give us appropriate data; however, patients can present in ways that can be identified by experienced clinicians, which cannot be broken down into words that will be universally understood. In addition, acute presentations require knowledge to be immediately accessible so that the appropriate action can be taken as soon as possible. Looking up facts in these scenarios may delay the management of the patient and compromise their outcomes.

In conclusion, it is currently unclear whether technology reduces the need to memorize large quantities of medical knowledge. In less routine non-acute medical settings, fully exploring management options using information technology may be more beneficial and in the best interests of our patients. Our pride as medical professionals often discourages this behavior. We question whether, in the cur- rent technological climate, testing our memory is more to do with satisfying our quest for knowledge, or if it really does provide benefit to our patients.

\section{Disclosure}

The authors declare no conflicts of interest in this communication.

\section{References}

1. Ward JP, Gordon J, Field MJ, Lehmann HP. Communication and information technology in medical education. Lancet. 2001;357(9258): 792-796.

2. Tang $\mathrm{H}, \mathrm{Ng} \mathrm{JH}$. Googling for a diagnosis - use of Google as a diagnostic aid: internet based study. BMJ. 2006;333(7579):1143-1145.

3. Haynes AB, Weiser TG, Berry WR, et al. A surgical safety checklist to reduce morbidity and mortality in a global population. $N$ Engl $\mathrm{J} \mathrm{Med}$. 2009;360(5):491-499.
Advances in Medical Education and Practice

\section{Publish your work in this journal}

Advances in Medical Education and Practice is an international, peerreviewed, open access journal that aims to present and publish research on Medical Education covering medical, dental, nursing and allied health care professional education. The journal covers undergraduate education, postgraduate training and continuing medical education

\section{Dovepress}

including emerging trends and innovative models linking education, research, and health care services. The manuscript management system is completely online and includes a very quick and fair peer-review system. Visit http://www.dovepress.com/testimonials.php to read real quotes from published authors.

Submit your manuscript here: http://www.dovepress.com/advances-in-medical-education-and-practice-journal 